\title{
Design and Implementation of an Autonomous Underwater Vehicle (AUV) with PTFE
}

Jebelli A*, Yagoub $\mathbf{C}$ and Dhillon $\mathbf{S}$

Faculty of Engineering, University of Ottawa, Ottawa, Canada

\begin{abstract}
In this paper, we presented a light, reliable underwater robot made of Poly Tetra Fluoro Ethylene (PTFE) which has a high safety coefficient against the forces being applied on it in different circumstances of the sea depths in addition to being light, cheap and also we presented a very quick and low-cost method for sealing off this robot made of Teflon.
\end{abstract}

Keywords: AUV; Poly Tetra Fluoro Ethylene (PTFE); Teflon; IMU; O-ring; Gasket Maker; Butyl

\section{Introduction}

Nowadays, manufacturing the underwater robots is associated with different challenges. Due to weight, intended depth and the size of robot it is very hard to choose an appropriate body which can meet all of the requirements of the robot and especially when the manufacturing cost is a major factor in designing.

Usually, due to installing sidelong accessories such as cameras, thrusters and the antenna on the robot, in addition to weight change, designer should apply some changes in the appearance of the robot to minimize or neutralize the forces applied on the body in the fluid that sometimes makes the implementation of the designed plan, according to the body material in real environment very time consuming and even impossible. Moreover, implementation of these changes in these kinds of robots will cost a lot for the manufacturer. In this project that we designed, there is a very light sample of an underwater robot made of Poly Tetra Fluoro Ethylene (PTFE) [1,2] with very high designing deviations which has the ability of carrying two thrusters, camera, antenna and sidelong accessories on its body is so reliable in addition to being so cheap and resistant against the applied forces on that in depth of water which in this paper we will explain it in detail and also we offer a very fast and highly reliable method for sealing the body of the robot to prevent water penetration into the body that prepares the robot for the operation in the short time which in carried out tests it showed approximately 600 hours which the sealing method is fully impervious.

\section{Body Design}

In this work, we designed a research prototype which main characteristics are the simultaneous use of two thrusters located in a specific angle so both vertical and horizontal forces needed are provided simultaneously. The change of angle can be made possible by the instant movement of an engine stopper which consumes much less energy than the constant movement of a thruster.

In designing this AUV, we included a mass shifter, first because of the thruster movement and second to make the maneuver possible in the direction of the pitch. The whole set can have two movement modes. In the first mode, the body should, by the help of the mass shifter, have a constant horizontal movement and its movement towards vertical and horizontal directions should be done through a change in the thruster angle. In the second mode, the thrusters should be kept fixed in a horizontal direction and the vertical movement should be made possible through a change in the body angle in the pitch direction.
The first mode is used wherever there is little room of maneuver or to pass obstacles while the second mode is used to preserve and store the source of energy and change in great depths. Note that this structure is innovative, and although some complications in terms of controlling issues can be expected, it is highly energy-saving (Figure 1).

\section{Locating Parts}

The valve \# 1 in Figure 2 used for placing charger cables, programmer the microcontrollers and the processor data cable. This valve enables the user to have access to the whole system without any need to open the whole body and follow- up damage to the sealing. The holes \#2 and
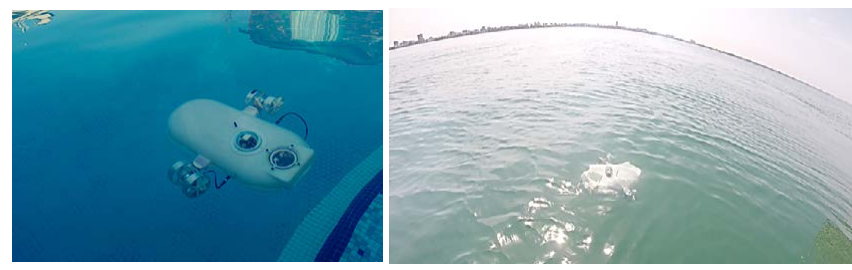

Figure 1: The robot is testing in the pool and the ocean.
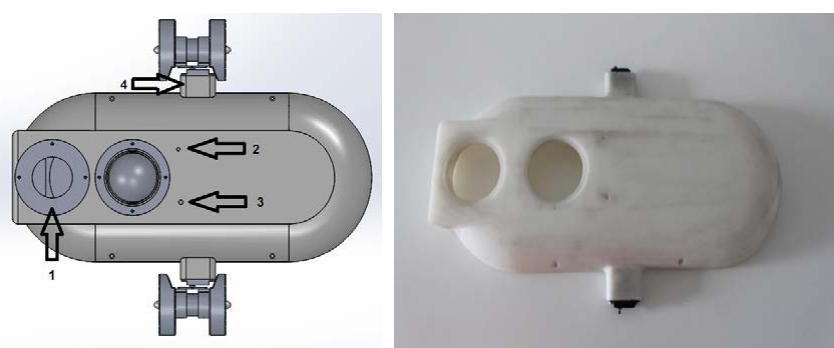

Figure 2: Access valve (1), antenna holes (2), pressure sensor (3), and dolly block of servo motor (4).

*Corresponding author: Jebelli A, Faculty of Engineering, University of Ottawa, Ottawa, Canada, Tel: +1 647687 3300; E-mail: ajebelli@uottawa.ca

Received January 04, 2018; Accepted January 29, 2018; Published February 05, 2018

Citation: Jebelli A, Yagoub C, Dhillon S (2018) Design and Implementation of an Autonomous Underwater Vehicle (AUV) with PTFE. Adv Robot Autom 7: 185. doi: 10.4172/2168-9695.1000185

Copyright: ( 2018 Jebelli A, et al. This is an open-access article distributed under the terms of the Creative Commons Attribution License, which permits unrestricted use, distribution, and reproduction in any medium, provided the original author and source are credited. 
\#3 in Figure 3 are for the pressure sensor and the antenna, respectively. It is to be noted that the form of body at the end, which is the access valve, is cubic to prepare more space for the valve.

The body is designed with the two dolly blocks \#4 shown in Figure 2 , in which servo motors will be placed to change the thruster angle.

The thickness of the body is $1 \mathrm{~cm}$ and the body is made of Teflon. There are two cameras, one above (main camera) and the other on the bottom. Considering the thickness of the body, some extra tools may be attached to the body upon necessity. Therefore, adding more thrusters in the required directions or a robot arm is possible.

In Figure 3, valve \#1 is a valve under the access valve, separated from the other sections by a wall to avoid possible leakage. Also, this space contains a step at the end to easily design the required board or sockets without any fear from making a hole in the body. Also, the batteries are in this space. The engine driver board is placed in the space provided by valve \#2. Valve \#3 is dedicated to locate the Mini PC and valve \#4 to initially locate the sensors. However, due to their high sensitivity, they have been relocated as in Figure 4: the circular space near the cape has been used for placing the Inertial Measurement Unit (IMU) and the compass sensors as in Figure 5. In this Figure, \#1 is related to the bottom camera.

\#2 and \#3 are for the sensors. Also, these parts have holes at the bottom covered by clear and thinner-than-body lens. The reason for this is to weaken the earth's electromagnetic waves inside the body.

Valve \#5 is for the parts that are connected to the middle sheet:

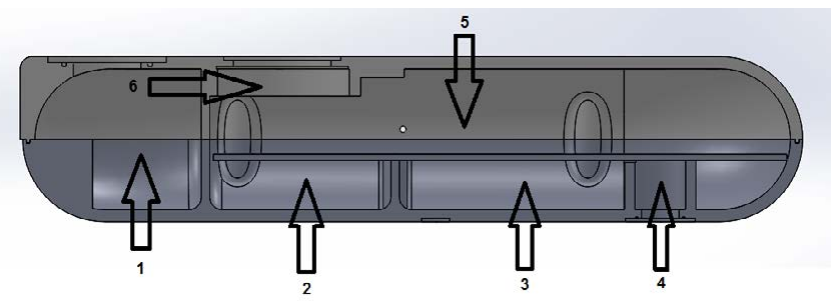

Figure 3: Six designed valves.

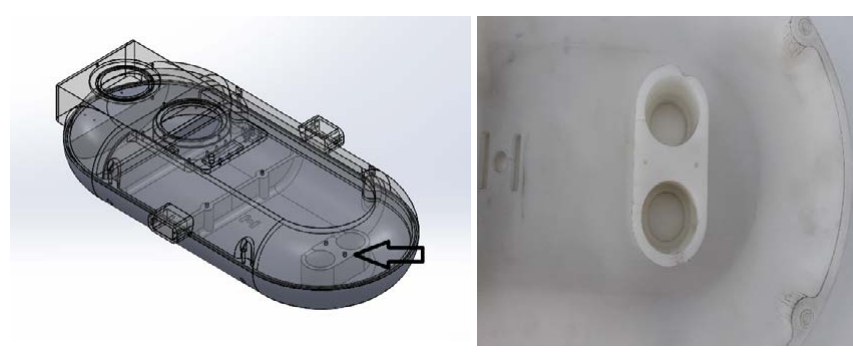

Figure 4: Location of the IMU and Compass sensors.
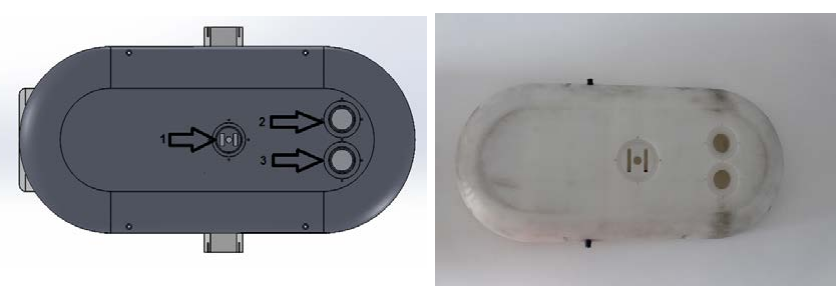

Figure 5: The bottom openings. the mass shifter and its motor. Finally, valve \#6 is for the main camera space as well as for the sensor board. Figure 6 shows the placement of the driver board, the bottom camera, the sensor board, the mass shifter, and the main camera.

\section{Body Material and Body Strength}

The body and its components are made of PTFE (Poly Tetra Fluoro Ethylene) Teflon. Teflon is a polymer with a molecule made of carbon fluorine atoms strongly connected to each other. This material is very strong and highly recommend due to its numerous plastic features. It is widely used in industry and has practical suitable features such as

- High resistance against chemical factors

- High resistance against adherence

- High dielectric features (electricity nonconductor).

However, one of its main advantages remains its flexibility. This material does not break even at a pressure of $0.7 \mathrm{~N} / \mathrm{mm}^{2}(700 \mathrm{kPa})$ $[3,4]$. However, in accordance with the ASTM D790 standard, plastic form and flexibility of Teflon in natural temperature is about 50-650 $\mathrm{N} / \mathrm{mm}^{2}[3,4]$. Teflon is also one of the best and valuable electrical insulations. It should be mentioned that Teflon retains this feature in different atmospheric, and temperature conditions as well as at different frequencies [3-5].

\section{Robot Isolation}

One of the crucial points to solve was how to efficiently isolate the robot from any possible leakage. First, a groove around the body was spotted and sealed with an O-ring. However, the body was deformed after machining the Teflon leading to leakage. We then considered a range of silicon glues with various percentages and Gasket Makers [6].

Yet, test showed that body twist imposed another leakage. Another alternative was to seal the robot from outside using paraffin, this material turns into liquid at $50-60^{\circ} \mathrm{C}$ and could be easily placed inside the groove while it sticks well to Teflon [7]. The problem of using Paraffin is its proper use. Given the body size, the possibility of making improper paraffin pouring is high, which would lead to tiny holes. Then, instead of paraffin, silicon basic materials were tested too. The merit of these materials compared to paraffin is they require less time for being dried. Yet, a problem is the possibility of leaving vents, thus the sealing cannot be completely guaranteed.

Finally, we opted for Butyl, it's a polymer which is known in the market as Acronal. Some kind of this material named Sorghum used to be applied for sealing valves and camera lenses. However, the industrial type is called Butyl, which is used as a means of sealing [8]. This paste, used in the form of plastic sticky bands, was applied after filling the external groove with a thin layer of base silicon glue. Note that each band of Butyl can be attached and removed few times, which presents a

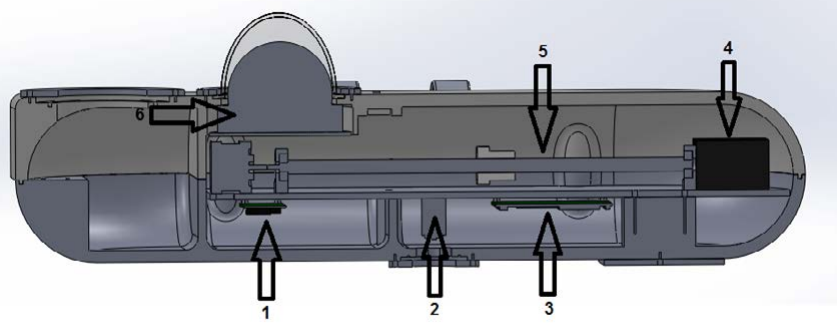

Figure 6: Locating internal components. 
significant advantage in case one need to access to the internal elements of the robot for repairs, replacements, or adjustments.

Therefore, the best method of putting silicon materials for sealing is as follows:

One of best types of silicone materials for sealing Teflon is Gasket Makers given their low friction level. These materials differ in what temperature or the tonnages they can bear. Even their formulas greatly depend on the producer company. For example, in the market of Gasket makers, Toyota and Mazda are two different kinds of gasket makers. In the suggested sealing, based on experience, the use of the two types together will work better. In the executed method, V-Tech Clear RTV Gasket Maker and Mazda Gasket Maker were used and upon that a layer of Polyurethane was placed.

First, Mazda Gasket Maker must be put between the surfaces as the washer. Placing the paste on the bottom edge before placing the upper edge or vice versa is a difficult task. Therefore, two parts of the body were first placed on each other, but just before fastening the screws, the paste was placed between the seal. Figure 7 shows this step.

In this step screws are fastened in order for the paste to stick to two surfaces as much as possible. Figure 8 shows this step. The step was also performed such that first the paste became dry, then the screws were fastened, but it showed leakage.

The estimated time for drying this volume of Gasket maker is 30 minutes. Upon becoming dry, the V-Tech Clear RTV Gasket Maker is executed on it which is clear and has no impact. Figures 9 and 10 show this step.

After around 20 minutes passing the dryness of the second layer, Polyurethane is applied. Figure 11 shows little use of this material

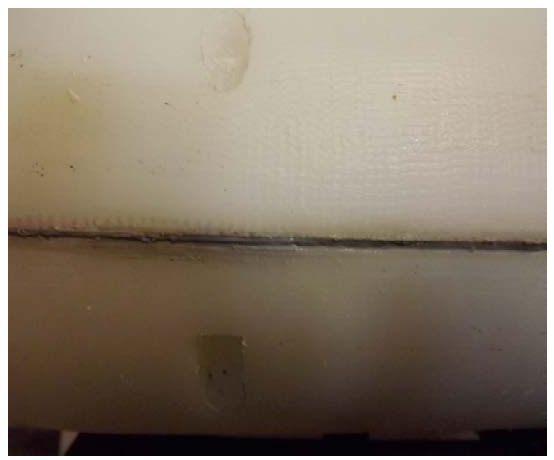

Figure 7: The paste between the seal.

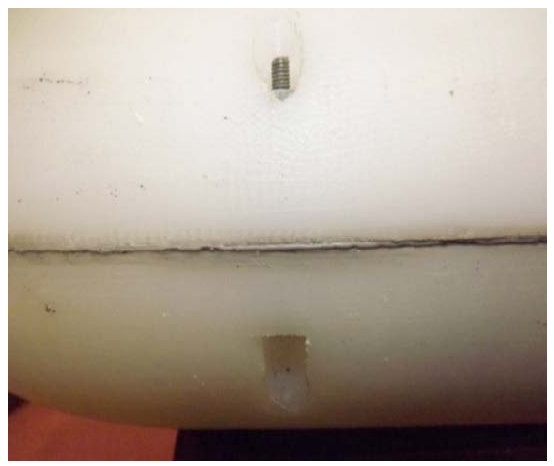

Figure 8: The screws.

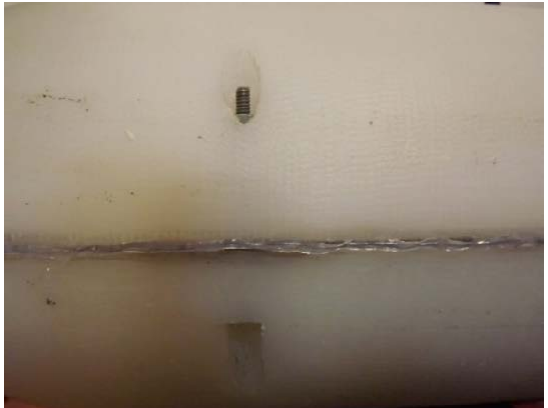

Figure 9: The V-Tech Clear RTV Gasket Maker and screws.

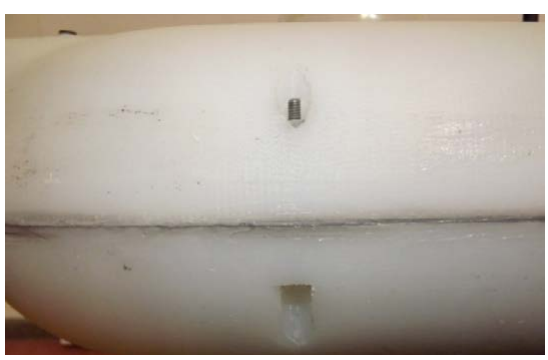

Figure 10: The V-Tech Clear RTV Gasket Maker.

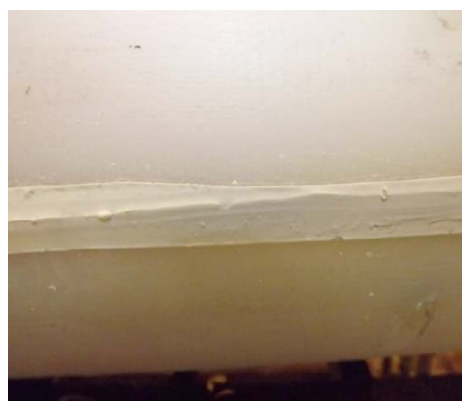

Figure 11: Polyurethane on the body.

which has been cut upon drying in the extra parts.

In the end, it should be mentioned that each of the above steps has been performed alone or with different schedules and orders. Finally, the best solution was with this method.

Note that we had to make a hole for the lens of the camera in the bottom as well as two other holes for the IMU and Magnetometer sensors to decrease the dielectric effect of Teflon. Fortunately, the bottom part of the body experienced less twist due to the existence of the wall, making the use of $\mathrm{O}$-rings possible.

This approach was also used to seal the thrusters. O-Rings are indeed the most common method for sealing moving parts whether be rotating or reciprocating. The fundamental problem with them in rotating shafts is power dissipation, in the sense that drivers should always spend some power to overcome the resistance caused by O-Ring. Therefore, we would have to add this amount of resistance to the torque and power requirements in our calculations as well as to coat the shaft and its above chamber with grease (Figure 12).

\section{Applied Pressures}

In this part, the underwater vehicle is analyzed in terms of 

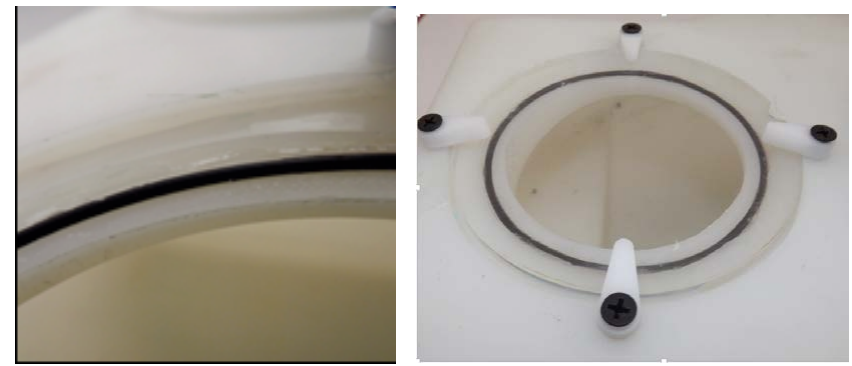

Figure 12: O-ring and O-ring groove.

pressure tolerance. The maximum depth for the vehicle was set to $8 \mathrm{~m}$. Considering the amount of 1,000 kilograms per cubic meter for water density, for each $1 \mathrm{~m}$ increase in depth, we have $10 \mathrm{kPa}$ pressure applied on the outer surface of the body. The pressure exerted on the body can be set as the difference between the pressure on the outer surface of the body, $P_{\text {out }}$ and the pressure on the inner surface of the body,

$$
\begin{aligned}
& P_{\text {in }}[9]: \\
& P_{t}=P_{\text {out }}-P_{\text {in }}
\end{aligned}
$$

The outer pressure can be expressed as:

$$
P_{\text {out }}=P_{\text {atm }}+P_{\text {watter }}
$$

with $P_{\text {atm }}$ the atmospheric pressure $(100 \mathrm{kPa})$ and $P_{\text {watter }}$, the pressure of the water column. Given that the maximum working depth of the vehicle is $8 \mathrm{~m}$, we get for an acceleration of gravity $\mathrm{g}$ of $9.81 \mathrm{~m} / \mathrm{s}^{2}$ :

$$
P_{\text {watter }} 1000 \times 9.81 \times 8 \cong 80 \mathrm{Kpa}
$$

And,

$$
P_{\text {out }=} 100+80 \mathrm{Kpa}
$$

Assuming that the internal pressure of the vehicle is the same as the atmospheric pressure of $100 \mathrm{kPa}$. Therefore, the total pressure exerted on the body is:

$$
P_{t=} 100+8-100=80 \mathrm{Kpa} .
$$

\section{Reliability Factor and Allowable Load}

In order to ensure the structure's safety, it is required to select the allowable stress tolerated by the structure that gives the appropriate load.

The load based on which the structure is designed may be different from the load actually applied on the structure. For example, measurements performed on a structure may be inaccurate due to errors in connecting the parts or to unknown vibrations, shocks or loads that were not considered during the design. The air corrosion, degradation and weather conditions can also alter materials conditions during their usage.

One way to determine the allowable load to design and analyze a structure is the use of a value called safety factor. The called safety is displayed as F.S and obtained by Judd and Knasinski [10]:

$$
F . S .=\frac{\sigma_{\text {fail }}}{\sigma_{\text {allow }}}
$$

Where $\sigma_{\text {fail }}$ is the failure load determined by the material test (can be found in tables related to the mechanical properties of the materials) and $\sigma_{\text {allow }}$ the allowable load based on the design.
The failure load for PTFE is set as 23 to $30 \mathrm{MPa}$ according to tests performed for the material. In this work, the lowest failure load value of $23 \mathrm{MPa}$ was considered and a safety factor of 3.5 was retained based on preliminary experiences and targeted application [11,12]. Therefore, $\sigma_{\text {allow }} \cong 6.57 \mathrm{Mpa}$. The properties required by PTFE material as well as the selected safety factor and allowable load by the structure are summarized in Table 1.

According to the failure load related to PTFE material, the maximum load to be applied on the body is $6.57 \mathrm{MPa}$.

\section{Anchor}

Figure 13 shows the location indicating the constraints. The green arrows on both sides of the vehicle and in the motors' arms are the places for the body anchor. Given that structural analysis is carried out statically, it is necessary to determine the anchor to perform the analysis.

The red arrows in Figure 14 represent the loading. In this analysis, loading is based on pressure and applied on the entire surface of body. The green arrows state for the place of anchor as mentioned before. Figure 15 shows the used meshing.

\begin{tabular}{|l|c|}
\hline$\sigma_{\text {fail }}-$ failure load of PTFE & $23 \mathrm{MPa}$ \\
\hline$E$ - the modulus of elasticity for PTFE & $0.5 \mathrm{GPa}$ \\
\hline$\rho$ - PTFE density & $2300 \mathrm{~kg} / \mathrm{m}^{2}$ \\
\hline F.S safety factory & 3.5 \\
\hline$\sigma_{\text {allow }}$ allowable load & $6.57 \mathrm{MPa}$ \\
\hline
\end{tabular}

Table 1: PTFE mechanical properties and selected safety factor.

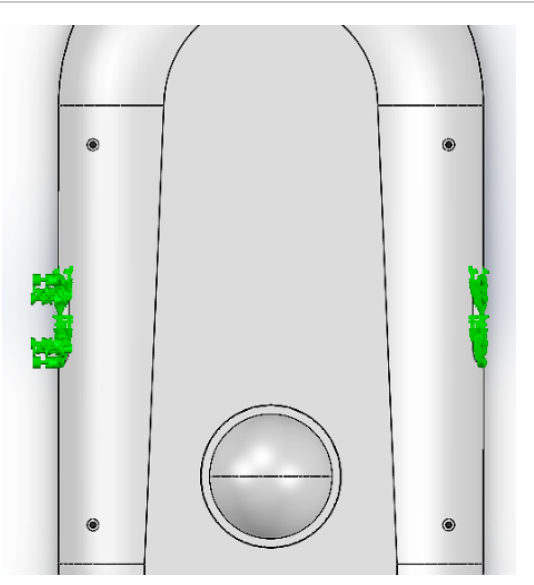

Figure 13: The location of anchor.

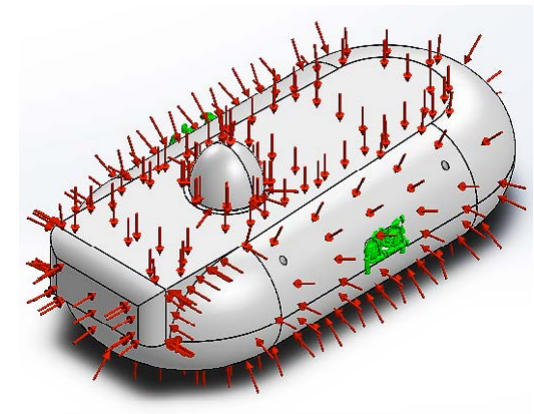

Figure 14: Loading. 
Citation: Jebelli A, Yagoub C, Dhillon S (2018) Design and Implementation of an Autonomous Underwater Vehicle (AUV) with PTFE. Adv Robot Autom 7: 185. doi: 10.4172/2168-9695.1000185

Page 5 of 7

\section{Results}

\section{Stress}

In general, the proportion of the force to the surface is called stress. There are two types of stress: Normal and shear stress. Energy intensity applied on unit area perpendicularly is called the normal stress and calculated as follows [13]:

$$
\sigma=\frac{F}{A}
$$

If the direction of the force is to the inside, it is called the compressive stress and presented as $\sigma_{c}$. If the direction of the force is to the outside, it is called tensile stress and presented as $\sigma_{t}$.

Energy intensity per unit area that is tangent to the surface is called the shear stress and presented as $\tau$. This stress can be obtained from the following equation [13]:

$$
\tau=\frac{V}{A}
$$

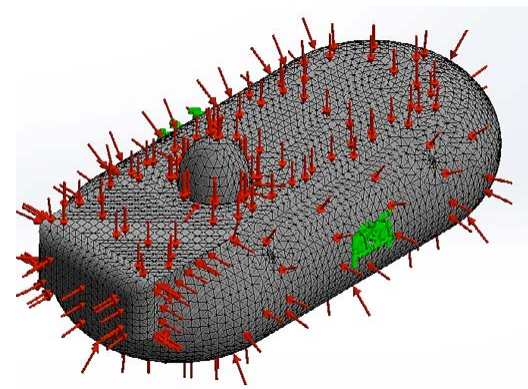

Figure15: Meshing

\section{Where: $\mathrm{V}$ is the shear force.}

One of the applied failure hypotheses is the strain energy or distortion energy hypothesis. This hypothesis predicts that failure happens due to yielding happens when the strain energy in a unit volume is equal to or greater than the strain energy related to yield tensile strength or a pressure on the same volume of the object. The output of this hypothesis is as follows:

$$
\sigma^{\prime} \geq S_{y}
$$

This equation suggests that failure occurs when Von Mises stress is greater than the matter yield stress.

Von Mises stress can be obtained from the following equation [14]:

$\sigma^{\prime}=\frac{1}{\sqrt{2}}\left[\left(\sigma_{x}-\sigma_{y}\right)^{2}+\left(\sigma_{y}-\sigma_{z}\right)^{2}+\left(\sigma_{z}-\sigma_{x}\right)^{2}+6\left(\tau_{x y}^{2}+\tau_{y z}^{2}+\tau_{z x}^{2}\right)\right]^{\frac{1}{2}}$

In this study the distortion energy failure hypothesis is used and the stress presented in the figure is Von Mises stress.

Figure 16 presents Von Mises stress changes in different parts of the body. The right Table presents the stress increase as well as changes in color. For further clarity the Table is presented in Figure 17 separately.

As it is presented in Figure 17, the maximum stress experienced by the body is $6.228 \mathrm{MPa}$.

The part of the body in which the maximum stress occurs is presented in Figure 18 (the black circle).

Figure 19 presents part of the body in which the stress is more than $3 \mathrm{MPa}$. As it can be observed in this figure the higher stresses have happened in the central parts of the upper body and central parts of the lower part of the body.

\section{Strain}

Strain is associated with stress through Hook's equation. According to Hooke's Law [15]:

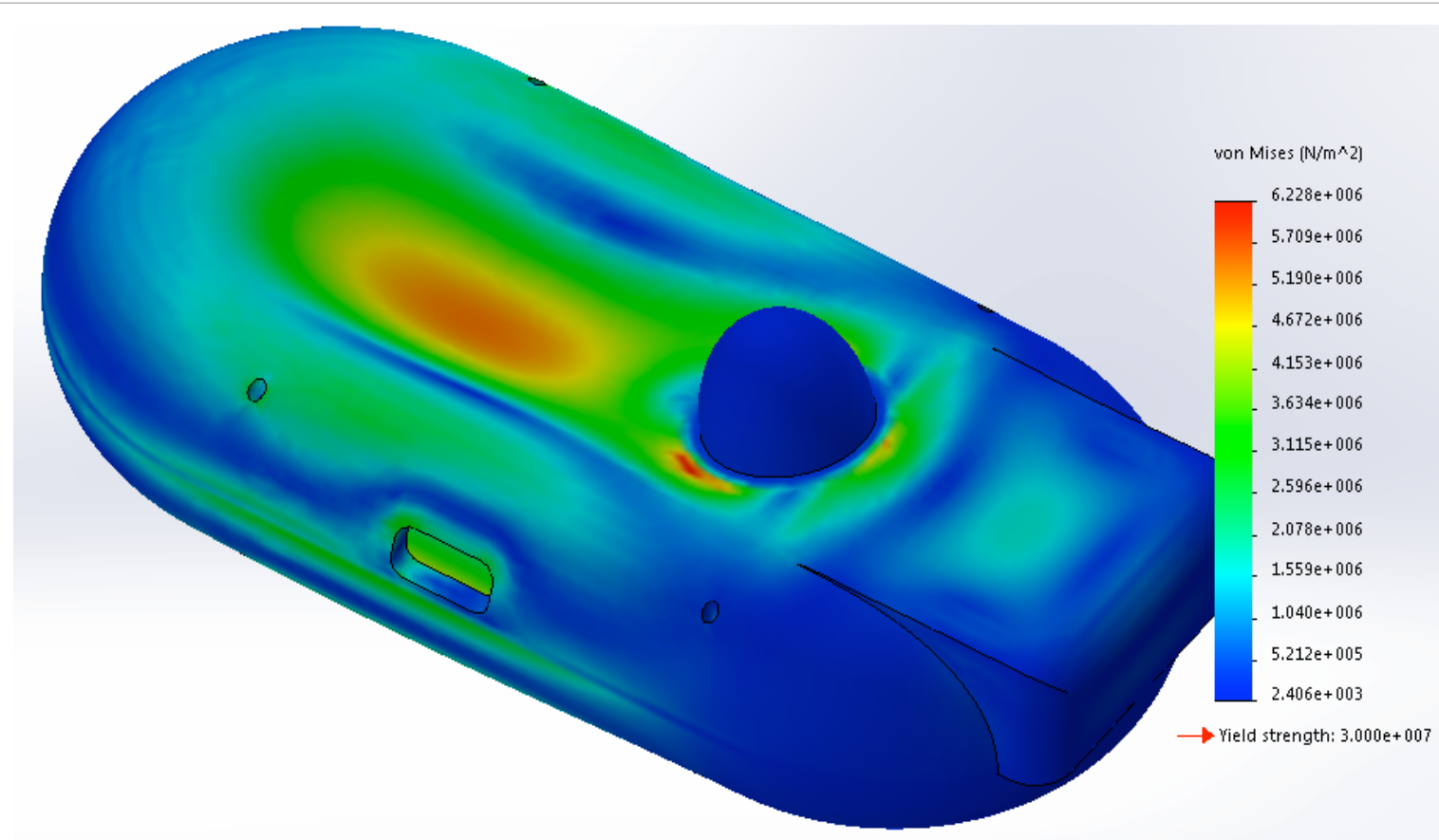

Figure 16: Stress variations. 
Citation: Jebelli A, Yagoub C, Dhillon S (2018) Design and Implementation of an Autonomous Underwater Vehicle (AUV) with PTFE. Adv Robot Autom 7: 185. doi: 10.4172/2168-9695.1000185

Page 6 of 7

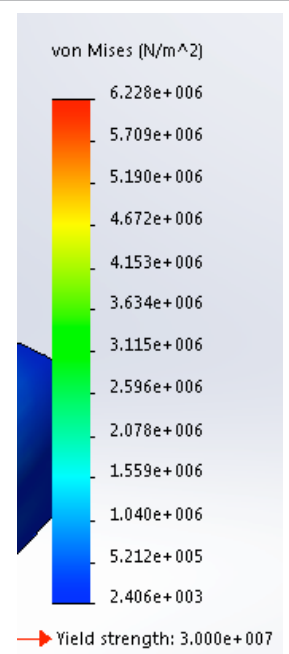

Figure 17: Stress Changes Table.

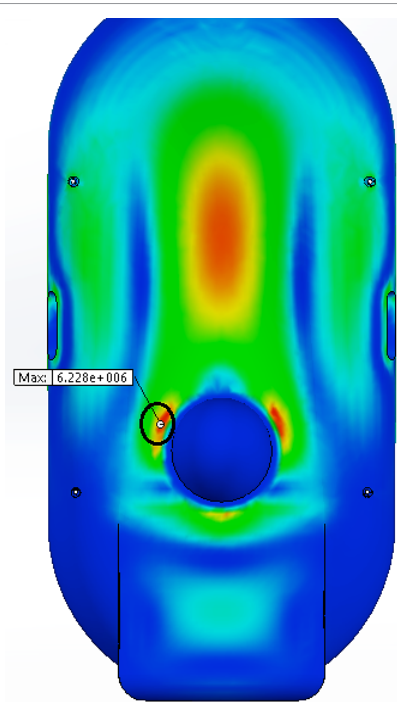

Figure 18: Region of maximum stress.

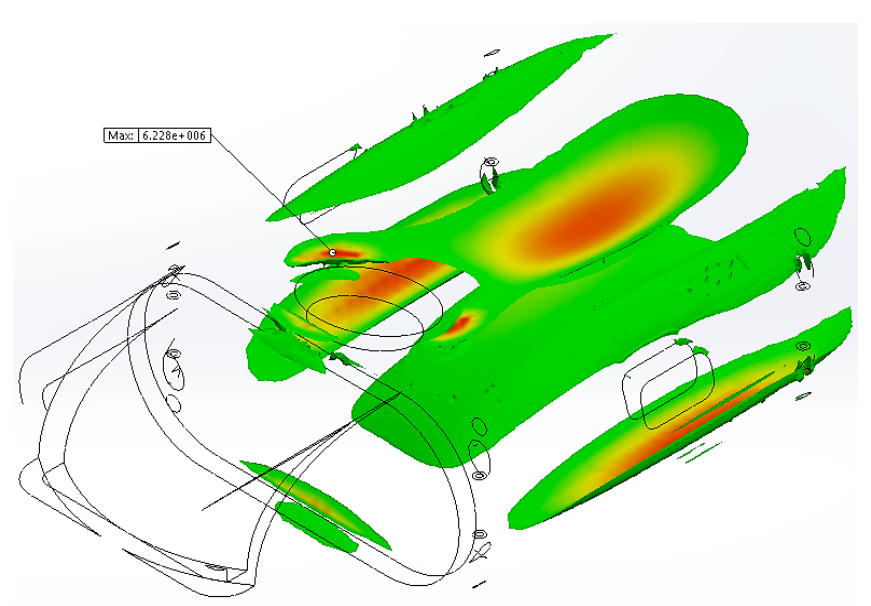

Figure 19: Stress more than $3 \mathrm{MPa}$.
$\sigma=\mathrm{E} \varepsilon$

Where:

$\sigma$ stress, $\mathrm{E}$ is coefficient of proportionality known as the modulus of elasticity, and $\varepsilon$ presents strain and is a dimensionless parameter.

Figure 20 changes in strain in different parts of the body. As shown, the maximum allowable stress applied on the body is $6.57 \mathrm{MPa}$ while the maximum applied stress on the body at a depth of $8 \mathrm{~m}$ is lower $(6.228 \mathrm{MPa})$, thus validating our design.

\section{Displacement}

Figure 21 shows the displacement of various parts of the body. The right table in the image presents increased displacement with warmer color and in millimeters. As can be seen the maximum displacement is $5.205 \mathrm{~mm}$. The maximum displacement is related to the point presented in Figure 22.

\section{Conclusion}

In this research, we presented a very small and lightweight underwater robot made of Teflon, which has two rotating thrusters and several different compartments for batteries, sensors, robot processor, cameras and antennas are implemented at exterior and interior parts of the robot. In this research, with regard to the static and dynamic tests carried out on the body of the robot, we showed that the Teflon material could be a proper choice for a underwater robot.

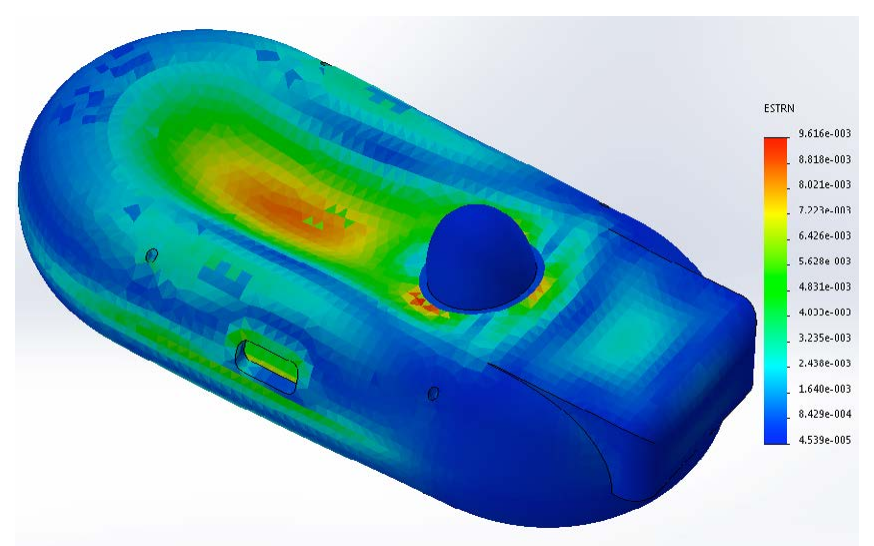

Figure 20: Strain changes

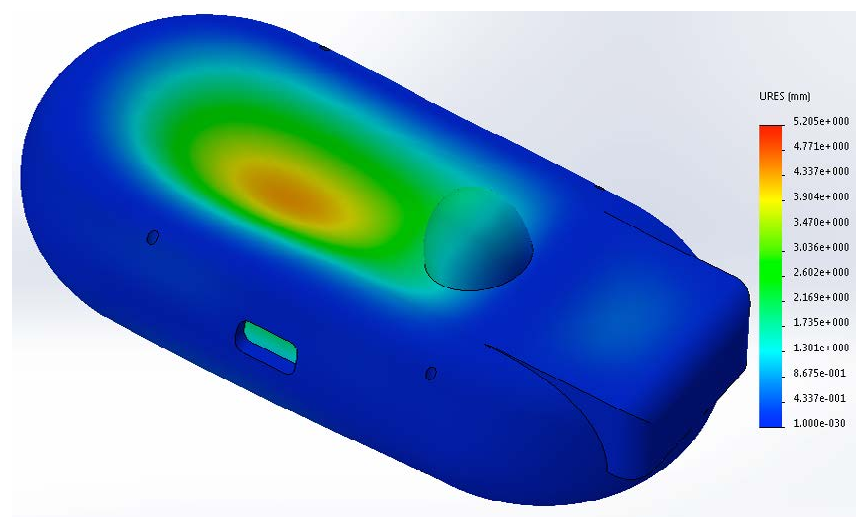

Figure 21: Displacement of the points in the body 
Citation: Jebelli A, Yagoub C, Dhillon S (2018) Design and Implementation of an Autonomous Underwater Vehicle (AUV) with PTFE. Adv Robot Autom 7: 185. doi: 10.4172/2168-9695.1000185

Page 7 of 7

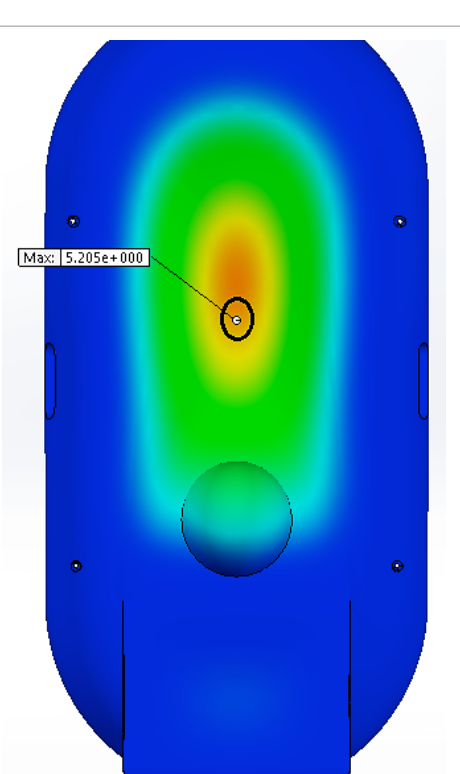

Figure 22: The point of maximum displacement.

Figure 21 shows the displacement of various parts of the body. The right table in the image presents increased displacement with warmer color and in millimeters.

As can be seen the maximum displacement is $5.205 \mathrm{~mm}$. The maximum displacement is related to the point presented in Figure 22.

However, insulation of the robot to prevent water penetration is worrying in this body material. Hence, we also have presented a quick and inexpensive method to insulating submarine robots made of Teflon, which is very efficient and reliable.

\section{References}

1. Institute of Technology (2010) ETH Zurich, Switzerland.

2. Astakhov VP, Shvets S (2004) The Assessment of Plastic Deformation in Metal Cutting. Journal of Materials Processing Technology 146: 193-202.

3. Wikol M, Hartmann B, Brendle J, Crane M, Beuscher U, et al. (2008) Expanded Polytetrafluoroethylene Membranes and their Applications. WL Gore and Associates, Inc., Elkton, Maryland, USA.

4. Teflon ${ }^{\circledR}$ PTFE fluoropolymer resin (2013) Properties Handbook.

5. Kurowski PM (2014) Engineering Analysis with SolidWorks Simulation 2014. Schroff Development Corp., SDC Publications, p: 499.

6. Fischell E (2008) Sealing Manual and Protocols: Cornell University Autonomous Underwater Vehicle Team.

7. Jackson E (2015) The Seal Man's O-Ring Handbook ${ }^{\mathrm{TM}}$, Harvard University Department of Physics.

8. PTFE Seal Design Guide (2011) Parker Hannifin Corp., Belgium.

9. Munson BR, Rothmayer AR, Okiishi TH, Huebsch WH (2012) Fundamentals of Fluid Mechanics, Wiley, ( $7^{\text {th }}$ edn.), p: 792.

10. Wikipedia (2016) The free encyclopedia, Factor of safety.

11. Sliney HE, Williams FJ (1982) Performance of PTFE-Lined, Composite Journal Bearings. NASA Technical Memorandum 82779, Lewis Research Center, Cleveland, Ohio.

12. Rae PJ, Dattelbaum DM (2004) The properties of Poly Tetra Fluoro Ethylene (PTFE) in compression. The International Journal for the Science and Technology of Polymers, Polymer 45: 7615-7625.

13. Khan AS, Wang X (2000) Strain Measurements and Stress Analysis, Pearson, 1 edn., p: 247.

14. Jong IC, Rogers BG, Springer W (2009) Teaching von Mises Stress: From Principal Axes to Non-Principal Axes. American Society for Engineering Education.

15. Mavko G, Mukerji T, Dvorkin J (2010) The Rock Physics Handbook. Tools for Seismic Analysis of Porous Media. ( $2^{\text {nd }}$ edn.), Elasticity and Hooke's law, pp: 21-80. 